\title{
Endovascular Management of Tandem Occlusion Stroke Related to Internal Carotid Artery Dissection Using a Distal to Proximal Approach: Insight from the RECOST Study
}

\author{
(D) G. Marnat, (DI. Mourand, (D). Eker, (D). Machi, (D). Arquizan, (D). Riquelme, DX. Ayrignac, (D) A. Bonafé, and (D). Costalat
}

\begin{abstract}
BACKGROUND AND PURPOSE: Internal carotid artery dissection is a common cause of stroke in young adults. It may be responsible for tandem occlusion defined by a cervical steno-occlusive carotid wall hematoma associated with an intracranial large-vessel stroke. Intravenous thrombolysis is associated with a poor clinical outcome in these cases, and endovascular treatment has not been specifically evaluated to date. Our aim was to evaluate endovascular treatment technical and clinical efficiency in this specific occlusion topography, in comparison with treatment of isolated anterior circulation stroke.
\end{abstract}

MATERIALS AND METHODS: As part of our ongoing prospective stroke data base started in August 2009 (Prognostic Factors Related to Clinical Outcome Following Thrombectomy in Ischemic Stroke [RECOST] Study), we analyzed all carotid artery dissection tandem occlusion strokes and isolated anterior circulation occlusions. All patients were selected for endovascular treatment according to clinicalradiologic mismatch, NIHSS $\geq 7$ and DWI-ASPECTS $\geq 5$, within 6 hours after onset. For carotid artery dissection, the revascularization procedure consisted first of distal recanalization by a stent retriever in the intracranial vessel. Following assessment of the circle of Willis, internal carotid artery stent placement was only performed in case of insufficiency. Carotid artery dissection treatment efficacy, safety, and clinical outcome were compared with the results of the isolated anterior circulation occlusion cohort.

RESULTS: Two hundred fifty-eight patients with an anterior circulation stroke were analyzed, including 57 with tandem occlusions (22\%); among them, 20 were carotid artery dissection-related occlusions (7.6\%). The median age of patients with tandem occlusions with internal carotid dissection was 52.45 versus 66.85 years for isolated anterior circulation occlusion $(P<.05)$; the mean initial NIHSS score was $17.53 \pm$ 4.11 versus $17.55 \pm 4.8(P=.983)$. The median DWI-ASPECTS was 6.05 versus $6.64(P=.098)$, and the average time from onset to puncture was 4.38 for tandem occlusions versus 4.53 hours in isolated anterior circulation occlusion $(P=.704)$. Complication rates and symptomatic intracranial hemorrhage were comparable in both groups $(5 \%$ versus $3 \%, P=.49)$. The duration of the procedure was significantly prolonged in case of tandem occlusion (80.69 versus 65.45 minutes, $P=.030)$. Fourteen patients with carotid artery dissection $(70 \%)$ had a 3-month $\mathrm{mRS}$ of $\leq 2$, without a significant difference from patients with an isolated anterior circulation occlusion (44\%, $P=.2$ ). Only 5 carotid artery dissections (25\%) necessitated cervical stent placement. No early ipsilateral stroke recurrence was recorded, despite the absence of stent placement in 15 patients (75\%) with carotid artery dissection.

CONCLUSIONS: Mechanical endovascular treatment of carotid artery dissection tandem occlusions is safe and effective compared with isolated anterior circulation occlusion stroke therapy. Hence, a more conservative approach with stent placement only in cases of circle of Willis insufficiency may be a reliable and safe strategy.

ABBREVIATIONS: ICD = internal carotid artery dissection; IOAC = isolated occlusion of the anterior circulation; IVT = intravenous thrombolysis

l. nternal carotid artery dissection (ICD) appears to be a common and increasingly diagnosed cause of ischemic stroke. It represents up to $20 \%-25 \%$ of stroke etiology in young adults ${ }^{1}$ and is the most common cause in patients younger than 55 years of age. ICD

Received August 13, 2015; accepted after revision January 3, 2016.

From the Department of Interventional and Diagnostic Neuroradiology (G.M.), Bordeaux University Hospital, Bordeaux, France; and Departments of Neurology (I.M., C.A., X.A.) and Interventional and Diagnostic Neuroradiology (O.E., P.M., C.R., A.B., V.C.), Montpellier University Hospital, Montpellier, France. is the consequence of a mural hematoma in the arterial wall, with separation of the intima from the media. The ischemic mechanism consists mainly of an internal carotid obstacle associated with intracranial clot migration, resulting in a so-called tandem occlusion. $^{2}$ Rarely, ICD may also be responsible for a hemody-

Please address correspondence to Gaultier Marnat, MD, Service de Neuroradiologie Diagnostique et Interventionnelle, Hopital Pellegrin, $\mathrm{CHU}$ de Bordeaux, Place Amélie Raba-Léon, 33000 Bordeaux, France: e-mail: gaultier.marnat@chu-bordeaux.fr

http://dx.doi.org/10.3174/ajnr.A4752 
namic stroke due to ICA lumen narrowing without intracranial occlusion in case of circle of Willis insufficiency. This last rare presentation was not addressed in the present study.

ICD with tandem occlusion represents a stroke subtype associated with a poor prognosis. ${ }^{3,4}$ Intravenous thrombolysis (IVT) ${ }^{5}$ is associated with poor recanalization rates and poor clinical outcomes. ${ }^{1,3}$ Several published series have reported very low recanalization rates in tandem occlusions, from $8 \%$ to $9 \%$ during the first 2 hours ${ }^{6,7}$ after thrombolytic drug infusion to $31 \%$ in the next 24-72 hours. ${ }^{4}$

Endovascular treatment is now increasingly considered and performed, especially following the results from randomized controlled trials (Multicenter Randomized Clinical trial of Endovascular Treatment for Acute Ischemic Stroke in the Netherlands [MR CLEAN], Endovascular Treatment for Small Core and Proximal Occlusion Ischemic Stroke [ESCAPE], Extending the Time for Thrombolysis in Emergency Neurological Deficits-Intra-Arterial [EXTEND-IA], Endovascular Revascularization With Solitaire Device Versus Best Medical Therapy in Anterior Circulation Stroke Within 8 Hours [REVASCAT], and Solitaire With the Intention for Thrombectomy as Primary Endovascular Treatment [SWIFT PRIME]), ${ }^{8-12}$ which demonstrated the superiority of combined strategies versus stand-alone intravenous treatments in large-vessel occlusion stroke. The particular, but not rare, tandem occlusion stroke subtype is still poorly explored. Despite promising results reported in the literature, ${ }^{13-22}$ most of the larger trials available on thrombectomy previously cited $^{23-25}$ excluded ICD. As a result, to date there has been only limited evidence predominantly using a first-generation device for mechanical thrombectomy ${ }^{26,27}$ and mixing tandem occlusion associated with ICD and ICA atheromatous stenosis. The aim of this study was to report the experience of our center in ICD tandem occlusion stroke and to compare the technical safety, efficacy, and 3-month clinical outcome in this subgroup with the results of our large-vessel anterior circulation stroke study (Prognostic Factors Related to Clinical Outcome Following Thrombectomy in Ischemic Stroke $[\text { RECOST }]^{28,29}$ ).

\section{MATERIALS AND METHODS \\ Sample}

All patients presenting with an anterior circulation ischemic stroke treated with an endovascular approach in our institution between August 2009 and April 2013 were retrospectively retrieved from our prospectively maintained stroke data base.

\section{Patient Selection}

The inclusion criteria were as follows: 1) patients with acute ischemic stroke presenting within 6 hours from symptom onset; 2) anterior circulation acute ischemic stroke; 3) DWI-ASPECTS $\geq 5 ; 4$ ) severe clinical deficits following physician evaluation, NIHSS $\geq 7$; 5) large-vessel occlusion (M1, M1-M2 junction, carotid terminus); and 6) premorbid modified Rankin Scale score of $\leq 2$.

\section{Decision-Making and Imaging}

The initial NIHSS and the Glasgow Coma Scale scores were assessed by a neurologist. MR imaging protocol consisted of diffu-
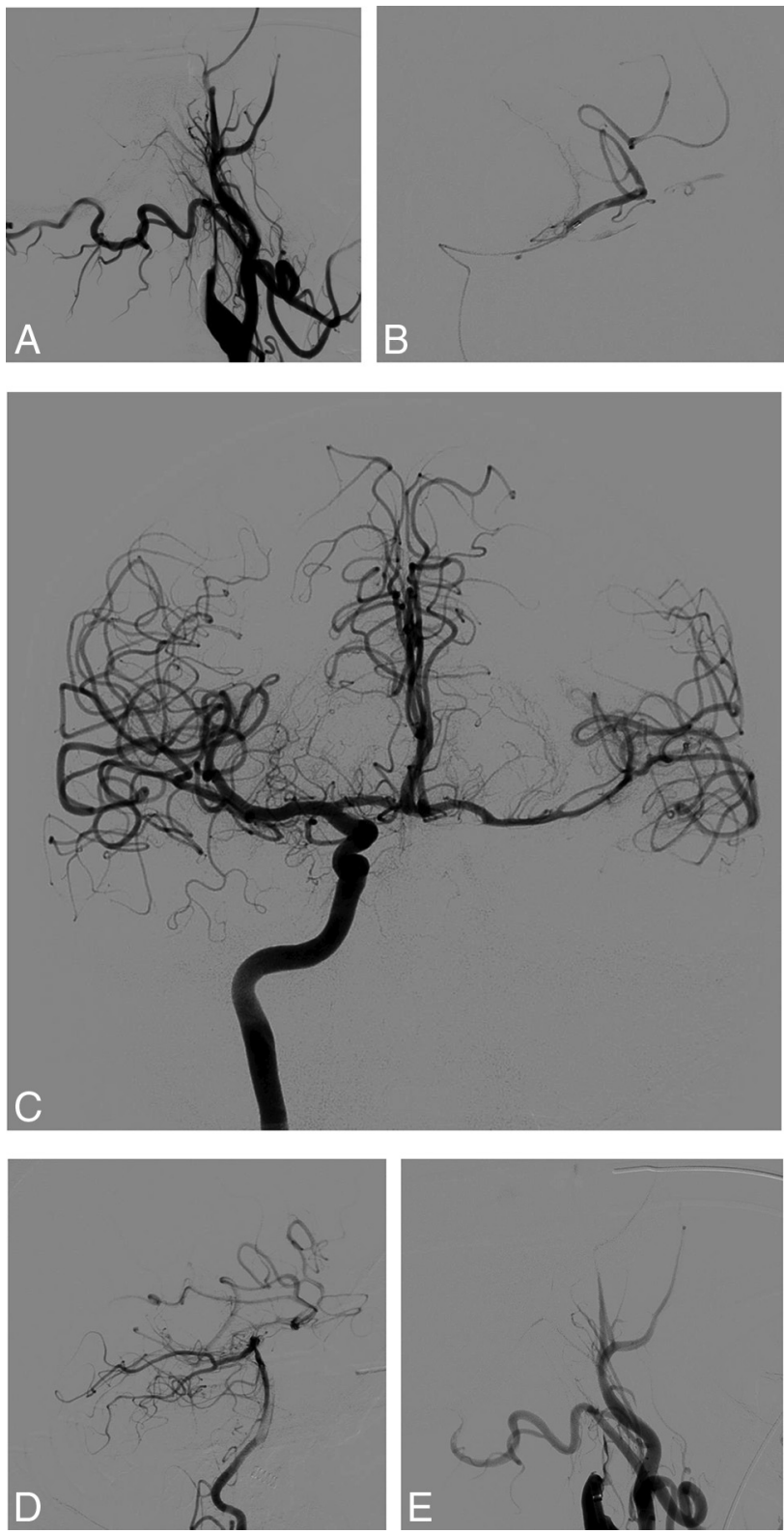

FIG 1. This patient presented with severe right hemiplegia and aphasia (NIHSS score $=20$ ). Initial MR imaging revealed a DWI-ASPECTS = 6 after 4.5 hours since symptom onset, associated with left tandem ICA and middle cerebral artery occlusions. The initial angiogram (A) demonstrates left internal carotid occlusion related to cervical dissection. We then carefully navigated the microcatheter through the dissected ICA to the intracranial occlusion $(B)$. Thrombectomy performed after contralateral femoral puncture and right ICA run shows a functional circle of Willis and no residual left $\mathrm{Ml}$ occlusion (C). The posterior communicating artery is also permeable as seen on the left vertebral artery run $(D)$. Consequently, we decided not to treat the cervical ICA dissection, and the artery was left in its initial condition $(E)$.

sion-weighted imaging, FLAIR, T2*, and MR angiography of the supra-aortic trunks. Tandem occlusion was suspected on initial imaging explorations and was confirmed on angiography with the morphologic aspect of the cervical segment of the internal carotid artery (Fig 1) associated with a proximal intracranial occlusion (carotid termination, M1 segment, and/or M1-M2 junction of the middle cerebral artery). 


\section{Intravenous Thrombolysis}

IVT $(0.9 \mathrm{mg} / \mathrm{kg}, 10 \%$ of the dose as a bolus and the remainder during 60 minutes) was administered to patients within a maximum of 4.5 hours after stroke onset. Conventional clinical and laboratory inclusion and exclusion criteria for IVT were applied.

\section{Endovascular Procedure}

We defined 2 types of treatment depending on the association with IVT: combined procedures and stand-alone thrombectomy. Combined procedures corresponded to endovascular treatment and IVT administered in the same time. Stand-alone thrombectomy was performed in case of contraindications for IVT.

Treatments were performed with the patient under general anesthesia. A 9F balloon-guiding catheter (Merci retriever; Concentric Medical, Mountain View, California) was introduced through a femoral sheath into the common carotid artery, and an initial angiographic run was performed to evaluate the occlusion. Isolated intracranial occlusions were treated with a triple coaxial approach: We placed an intermediate $5 \mathrm{~F}$ guiding catheter (5MAX and 5MAX ACE; Penumbra, Alameda, California) into the distal internal carotid artery upward; a 0.021-inch microcatheter (Headway; MicroVention, Tustin, California) was used to cross the thrombus over a 0.014-inch microwire (Transend 014; Stryker, Kalamazoo, Michigan; or Traxcess; MicroVention). Mechanical thrombectomy was performed with a Solitaire FR (Covidien, Irvine, California) or Trevo (Stryker) system after inflation of the balloon-guiding catheter, under manual aspiration through the intermediate catheter to prevent clot fragmentation and embolism.

In cases of tandem occlusion, we performed an angiographic evaluation to determine the cause (atheromatous disease or dissection). In cases of obstruction related to cervical ICD, a $0.021-$ inch microcatheter was navigated through the true lumen of the dissection over a microwire. The intermediate $5 \mathrm{~F}$ guiding catheter was then advanced over the microcatheter into the distal internal carotid artery. Intracranial thrombus retrieval was performed in the same manner as that for isolated occlusion by using a Solitaire FR (Covidien) or Trevo (Stryker) system, which was fully deployed and gently withdrawn with synchronous manual aspiration through the $5 \mathrm{~F}$ intermediate guiding catheter.

The result of intracranial recanalization was evaluated by using the Thrombolysis in Cerebral Infarction score. Successful recanalization was defined as TICI $2 b$ or 3 .

If intracranial recanalization was achieved, the next step consisted of a contralateral femoral puncture and an angiographic run through the contralateral common carotid artery and eventually through the vertebral arteries to assess the circle of Willis functionality. In particular, the efficiency of anterior and posterior communicating arteries was assessed. While endovascular treatments were performed with the patient under general anesthesia, our only criterion to evaluate circle of Willis efficiency was angiographic. As previously demonstrated, ${ }^{30}$ we focused on the anterior and posterior communicating artery permeability and bilateral venous phase comparison. If venous drainage was symmetric or delayed $<2$ seconds, the circle of Willis was efficient. If there was no supply from the communicating artery or if venous drainage was significantly delayed ( $>2$ seconds), we considered stent placement in the dissected internal carotid artery.

In case of cervical stent placement, the 0.014 -inch microwire was placed into the petrous segment of the carotid artery to preserve distal access in the true arterial lumen. The balloon-guiding catheter and the $5 \mathrm{~F}$ intermediate catheter were re-placed into the common carotid artery, just before carotid bifurcation. In case of persisting occlusive dissection, ICA stent placement was performed.

A 500-mg bolus of aspirin was administered intravenously. A carotid stent (Wallstent; Boston Scientific, Natick, Massachusetts) or LEO stent (Balt Extrusion, Montmorency, France) was navigated and deployed in the dissected segment. No additional angioplasty was required. Adequate position and opening of the stent were immediately assessed angiographically. Several stents might be needed if dissection was extensive and occlusive on the upper cervical and prepetrous segments.

Continuation of antiplatelet therapy was discussed, depending on hemorrhagic transformation detected by 24 -hour imaging. If no significant intraparenchymal hemorrhage appeared, dual antiplatelet therapy was performed for 3 months. One single antiplatelet treatment was then maintained during 1 year.

In case of major hemorrhagic transformation (parenchymal hematoma-1, parenchymal hematoma-2), antiplatelet therapy was stopped at the acute phase. Depending on the follow-up CT or MR imaging during the postoperative period, the antiplatelet therapy restart was discussed by the medical team.

Figure 1 illustrates a typical procedure according to our protocol.

\section{Follow-Up}

CT was performed immediately after each procedure to detect any hemorrhagic intracranial complication. A follow-up control CT or MR imaging was performed 24 hours after the acute therapy to assess infarction volume and hemorrhagic status. Hemorrhagic transformation was defined according to European Cooperative Acute Stroke Study (ECASS) classification among none, hemorrhagic infarction-1, hemorrhagic infarction-2, parenchymal hematoma-1, or parenchymal hematoma-2. Symptomatic intracranial hemorrhage was defined as a documented hemorrhage associated with a decline of $\geq 4$ points in the NIHSS. If no hemorrhage was present, antiplatelet drugs were prescribed.

Device-related complications were also reported. Embolic complications were defined as an angiographic occlusion in a previously unaffected vascular territory observed on the angiography after clot removal and associated with new ischemic changes on 24-hour CT or MR imaging.

NIHSS was measured following recovery from anesthesia, at 24 hours, and at discharge. Patients were followed up after 3 months to evaluate their disability by using the mRS. Clinical outcome was quantified by 3 -month mRS and mortality. Favorable outcome was defined as an $\mathrm{mRS}$ of $\leq 2$.

\section{Statistical Analyses}

We performed a global description of all the samples, giving the frequencies of each category for quantitative data. The distribution of those quantitative variables was not always Gaussian, so 
their description was realized with average, SD, median, and interquartile range. Comparison between groups was realized with average comparison tests (Student or Wilcoxon) for quantitative data and the $\chi^{2}$ or Fisher test for qualitative data. The significance threshold was $5 \%$ for all tests.

\section{RESULTS}

\section{Sample}

Between August 2009 and April 2013, 258 patients with an anterior circulation ischemic stroke were identified. Mean age was $66.2 \pm 14.14$ years, and median NIHSS score was 18 (range, 4-29). The baseline characteristics of the population are given in Table 1. Of 258, 179 procedures were combined (69.4\%) and 79 consisted of stand-alone mechanical treatments (30.6\%). Fiftyseven patients had tandem occlusion, and 201 had simple intracranial occlusion (M1 or M1-M2 junction or terminal internal carotid artery). Among patients with tandem occlusion, 37 occlusions were due to carotid atheromatous disease and 20 to ICD. Except for undetermined timing such as wake-up strokes, the average time from symptom onset to arterial puncture was $4.5 \pm$ 1.35 hours; range, $1.75-8.35$ hours).

Patients with atheromatous tandem occlusion were excluded from the study.

In the ICD group, patients were significantly younger than those belonging to the isolated occlusion of the anterior circulation (IOAC) group, 52.45 versus 66.85 years $(P<.05)$. There was a masculine predominance: $70 \%$ in the ICD group versus

Table 1: Population and stroke characteristics

\begin{tabular}{lcccc}
\hline & \multicolumn{3}{c}{ Average } \\
& Values (\%) & Values & Median & Range \\
\hline Age (yr) & & 66.02 & 69 & $22-90$ \\
Sex & & & & \\
$\quad$ Male & $135(52.33)$ & & & \\
$\quad$ Female & $123(47.67)$ & & & \\
Hypertension & $140(54.26)$ & & & \\
Smoking & $73(28.29)$ & & 18 & $3-29$ \\
NIHSS score & & 17.46 & 18 \\
ASPECTS & 6.51 & 7 & $2-10$ \\
Time between onset and & & 4.5 & 4.42 & $1.75-8.35$ \\
$\quad$ arterial puncture (hr) & & & & \\
Intravenous thrombolysis & $179(69.38)$ & & & \\
$\quad$ association & & & & \\
\hline
\end{tabular}

$47 \%$ in the IOAC group $(P<.05)$. In contrast, stroke characteristics did not differ significantly: NIHSS score, ASPECTS, time from onset to puncture, and IVT association. Characteristics and comparability of the 2 studied groups are summarized in Table 2 .

\section{Procedural Results and Early Evolution}

Intracranial recanalization (TICI $2 \mathrm{~b}$ or 3 ) was achieved for 14 patients $(70 \%)$ in the ICD group and 164 patients $(82 \%)$ in the IOAC group. This was not significantly different $(P=.23)$. Two stent retriever passes were needed, on average, for both groups, without any significant difference $(P=.112)$. However, the total duration of the revascularization procedure was significantly prolonged in case of tandem occlusion (80.69 versus 65.45 minutes, $P=.030)$.

Among the ICD population, 5 (25\%) patients finally required cervical internal carotid stent deployment. Stent placement was feasible in all cases when chosen without catheterization issues. There was no thromboembolic event related to stent placement. Figures 1 and 2 represent the 2 different types of procedures, depending on circle of Willis functionality.

Symptomatic intracranial hemorrhage affected 1 patient $(5 \%)$ in the ICD group, whereas it concerned $9(4.5 \%)$ of those with IOAC, without a significant difference $(P=.49)$. In the case of the patient with ICD, significant intracranial bleeding occurred early in the intensive care unit after an unfavorable mechanical revascularization (TICI score $=1$ ) and cervical carotid stent placement. This patient was $\mathrm{mRS}=4$ at the end of follow-up. The stent was still patent on the 3-month follow-up CTA.

Periprocedural complications consisted of 2 embolic migrations in the ICD group (10\%). In the IOAC group, 22 complications were reported $(11 \%, P=.10)$ : 16 embolic migrations, 2 proximal arterial perforations, 2 distal per procedural bleedings, 1 severe groin puncture complication requiring an operation, and 1 device breakage.

\section{Three-Month Clinical Assessment}

In the ICD group, no patient was lost to follow-up, whereas 7 were in the IOAC group. After 3 months, 14 (70\%) of the 20 patients from the ICD group had a favorable outcome. On the other hand, 92 among 183 (50.3\%) available patients treated for IOAC had an $\mathrm{mRS} \leq 2$. This was not significantly different $(P=.093)$. Mortality rates were $10 \%$ in the ICD group (2 patients) and $15.4 \%$ in the IOAC group (31 patients), without a significant difference.

In the subgroup of patients who benefited from ICA stent placement, 2 of them $(40 \%)$ had a 3 -month mRS $\leq 2$ $(1 \mathrm{mRS}=0$ and $1 \mathrm{mRS}=1)$. Two patients had a poor neurologic outcome $(\mathrm{mRS}=4$ and 5$)$, and 1 died.

In the unstented subgroup, $11 \mathrm{pa}$ tients $(73 \%)$ had a satisfactory clinical outcome ( 4 patients were $\mathrm{mRS}=0 ; 3$ patients, $\mathrm{mRS}=1$; and 4 patients, $\mathrm{mRS}$ $=2)$. The remaining 4 had poor neurologic outcome $(n=3)$ or died $(n=1)$.

Significant differences. 

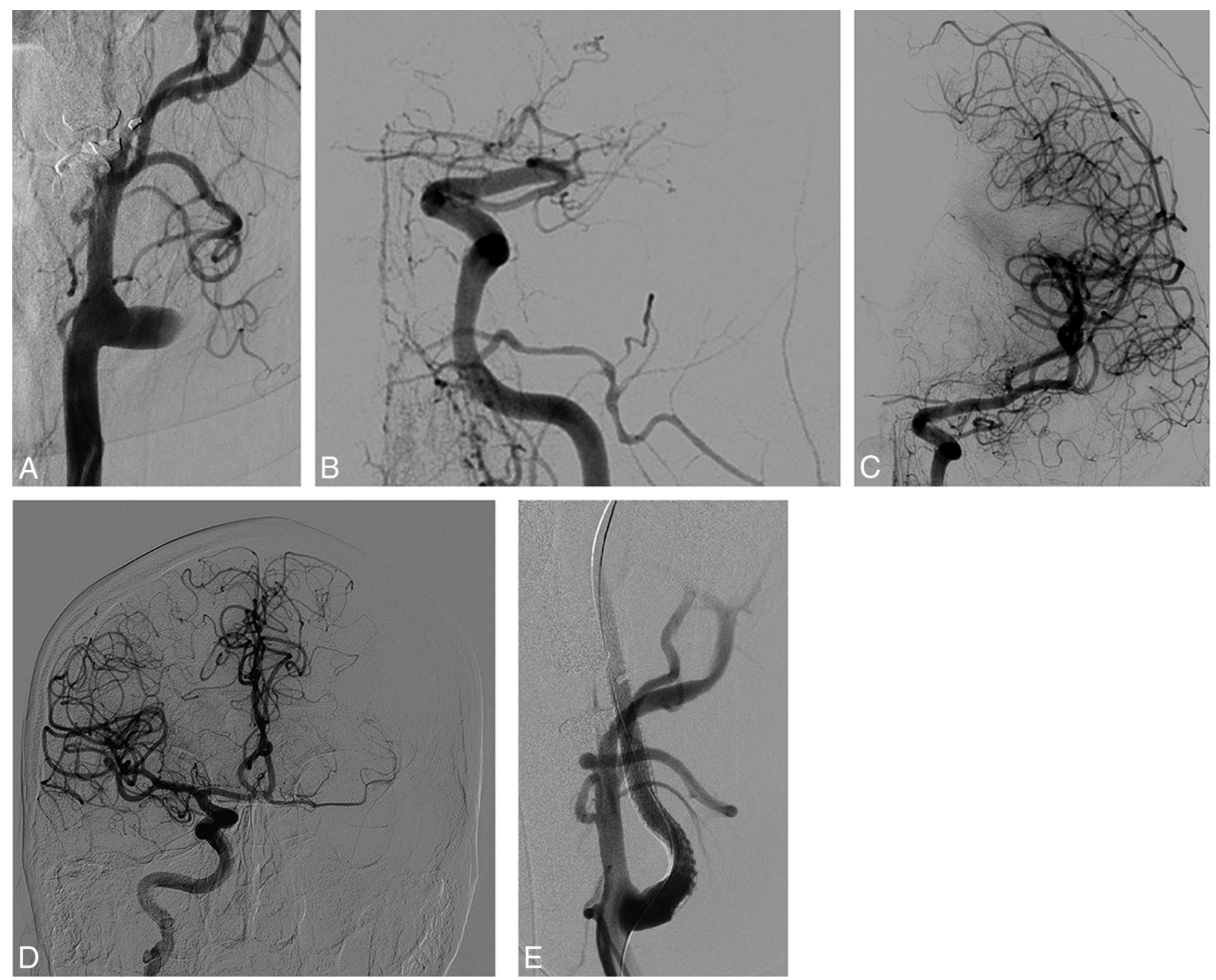

FIG 2. This acute tandem occlusion related to left cervical internal carotid dissection with a downstream intracranial M1 embolus was responsible for right hemiplegia and aphasia (NIHSS score $=22$ ). The first angiographic $(A)$ run demonstrated postbulbar internal carotid occlusion. After we navigated through the dissected segment, an intracranial initial angiogram confirmed the M1 thrombus (B). Complete intracranial recanalization was performed with 1 stent retriever pass (C). Thus, a contralateral internal carotid run revealed insufficient filling of the left MCA territory through the anterior communicating artery (D). In this case, cervical internal carotid stent placement of the dissected occlusive segment was mandatory (E). Clinical evolution was favorable (mRS $=1$ after 3 months).

Table 3: Angiographic results, complication rates, and clinical follow-up

\begin{tabular}{lccc}
\hline & $\begin{array}{c}\text { Tandem Occlusion } \\
\text { Related to Internal } \\
\text { Carotid Dissection } \\
\text { Group }(\boldsymbol{n}=\mathbf{2 0})\end{array}$ & $\begin{array}{c}\text { Isolated } \\
\text { Intracranial } \\
\text { Occlusion Group } \\
(\boldsymbol{n}=\mathbf{2 0 1})\end{array}$ & P Value \\
\hline Favorable recanalization, TICI 2b and 3 & $70 \%$ & $82 \%$ & .23 \\
Procedure duration (median) (min) & 74 & 47 & .030 \\
Median No. of intracranial device passes & 2 & 2 & .112 \\
Internal carotid stenting & $5 / 20(25 \%)$ & $3 \%$ & .49 \\
Significant hemorrhagic rate & $5 \%$ & $50 \%$ & .093 \\
$\begin{array}{l}\text { Clinical favorable outcome after 3 months } \\
\quad \text { (mRS } \leq 2)\end{array}$ & $70 \%$ & & \\
\hline
\end{tabular}

vessel occlusion, its efficiency is limited. Kim et $\mathrm{al}^{7}$ reported an early arterial recanalization after IVT in $9.4 \%$ of cervical vessel occlusions after 2 hours. Engelter et $\mathrm{al}^{1}$ obtained a significant clinical improvement in only $36 \%$ of patients with stroke due to acute internal carotid dissection, despite the young age of the subgroup.

The endovascular approach remains poorly studied. Indeed, prospective data are scarce because tandem occlusion is

No stroke recurrence was observed in the unstented ICD group. The results are summarized in Table 3.

\section{DISCUSSION}

Tandem occlusion stroke is an important therapeutic issue with poor prognosis, accounting for roughly $20 \%$ of large-vessel occlusion strokes. ${ }^{13,4}$ Since the early 1990s, IVT has been the first-line medical treatment widely prescribed. ${ }^{31-34}$ However, in cervical considered an exclusion criterion in many cohorts such as Solitaire FR With the Intention For Thrombectomy (SWIFT), SWIFT PRIME, Solitaire FR Thrombectomy for Acute Revascularization (STAR), and Thrombectomy REvascularization of Large Vessel Occlusions in Acute Ischemic Stroke (TREVO 2). ${ }^{23-25,35}$ Recently, MR-CLEAN, ESCAPE, and EXTEND-IA ${ }^{9,11,12}$ demonstrated the efficiency and safety of combined strategies in anterior 
circulation single proximal occlusion. Nevertheless, there was no subgroup analysis for patients with cervical dissection. Most of the recent literature data reported a mix of atheromatous and dissection, pooled as a single anatomic description so-called "tandem occlusion.” From a nosologic point of view, it looks confusing to associate 2 different diseases in different populations of patients with a different physiopathologic origin in a unique strategic approach. We consider these 2 entities completely different. Patients with ICD are younger and more prone to present with a very good circle of Willis to justify a simple intracranial treatment. Moreover, if the recurrence rate of stroke is proved in ICA atheromatous stenosis, ${ }^{36,37}$ the stroke recurrence from ICD after efficient medical therapy is very low. ${ }^{38}$ In this spirit, we usually tend to be conservative for ICD lesions but more aggressive with atheromatous stenosis, which is more prone to induce an ipsilateral stroke recurrence.

Our results by using this simple strategy allowed a satisfying intracranial revascularization in $70 \%$ of cases but also a substantial clinical recovery. Of course, the age of the subgroup positively influences the results in favor of the ICD subgroup, with a $70 \%$ rate of good outcome. Nevertheless, this study supports the hypothesis that ICD tandem occlusion stroke may be a very good indication for mechanical therapy and needs to be included in standard guidelines.

Thus, many approaches have been described to date, in particular anterograde revascularization. ${ }^{39-41}$ In this case, recanalization is performed first in the cervical internal carotid artery, most often by stent placement, and second in the intracranial vessel. Even if good results had been demonstrated with satisfying revascularization rates and acceptable clinical outcomes (range, 41\%$54 \%$ ), in our opinion, this method is not optimal. First, the procedural time used for carotid stent placement increases the time from symptom onset to intracranial revascularization, resulting in increased final necrotic core volume, when a direct intracranial revascularization will offer immediate brain flow through the circle of Willis in many cases. Second, complex stent placement may be needed in case of extensive dissection with a systematic need for antiplatelet therapy to ensure stent patency during the postoperative period, increasing the risk of hemorrhagic transformation.

Our approach is based on an understanding of the anatomic parameters. We believe it is necessary to evaluate the completeness of the circle of Willis, which requires a contralateral femoral puncture, allowing selective contralateral common carotid and eventually vertebrobasilar catheterizations. In this young stroke subpopulation, contralateral exploration is simple. It does not prolong the revascularization procedure because the circle of Willis assessment is performed after intracranial revascularization, when cerebral blood flow has already been restored.

First focused on internal carotid artery treatment, the anterograde approach would slow down intracranial recanalization, which is an essential end point and the main target of the treatment. Indeed cervical stent placement may take time, especially in the dissection situation, in which navigation takes place in an already-injured artery that could also be tortuous. In addition, worsening of the mobilization of in situ thrombus during stent deployment against the wall hematoma has already been observed in previous experience. ${ }^{42}$

Navigation inside the dissected artery is the main technical difficulty. The classic pitfall is catheterizing the false lumen, with the potential risk of dissection extension. Indeed, the stenosed or occluded cervical segment of the internal carotid artery relegates the operator to a blind navigation, only guided by the smooth progression of the microwire. In our experience, there has not been any iatrogenic complication during this specific stage. Nevertheless, we still believe that this maneuver remains a potential risk.

One of the major points of our rationale is anticoagulation and antiplatelet management. In the acute phase, patients with stroke carry an increased risk of hemorrhagic transformation of the infarction territory, depending especially on its size and the hemostasis status. The difficulty is because acute carotid stent placement necessitates antiplatelet drugs. These necessarily increase the risk of a hemorrhagic event, but in-stent thrombosis could potentially lead to new embolic events. In the context of acute stroke, dual antiplatelet drug introduction is not an established practice and relies more on empiric assessment based on stroke extent, postprocedure blood-brain barrier disruption, and so forth-all this with a potentially negative impact on clinical recovery.

This antiplatelet-related hemorrhagic risk is illustrated by our patient who presented with a symptomatic intracranial hemorrhage after 24 hours, while she previously benefited from ICA stent placement during a revascularization procedure. Comparing our stented and unstented subgroups was not easy, given the small number of patients in each group.

Still we think that limiting stent implantation should permit a reduction in the postprocedural complication risk.

Hence, distal to proximal revascularization appears to be a truly appealing alternative. In our experience, most of cases did not require any cervical carotid treatment because only 5 patients (corresponding to $25 \%$ of our population) required stent placement. This approach allows a quicker procedure to reach intracranial recanalization. In addition, no stroke recurrence was observed in the unstented ICD group, making this strategy a reliable option in the management of ICD with intracranial occlusion.

In our daily practice, triaxial access is a common endovascular approach. Our aim is to reach, as quickly as possible, the intracranial occlusion and to minimize intra-arterial maneuvers and complications. Positioning a $5 \mathrm{~F}$ intermediate guiding catheter into the distal ICA facilitates thrombectomy maneuvers, first by providing more support and stability to the system and second by allowing a rapid recatheterization in case of failed thrombectomy, avoiding the need for crossing the injured cervical ICA again.

Following intracranial reopening, the intermediate guiding catheter is withdrawn, leaving only a microwire inside the ICA to preserve access for potential cervical stent placement.

The postoperative hemorrhagic risk was tolerable. We reported $5 \%$ symptomatic intracranial hemorrhage, which is a comparable rate in the IOAC population. Besides, intracranial hemorrhages of the infarcted territories were mostly asymptomatic and limited and did not influence the clinical evolution ob- 
served in cases of IOAC. We did not encounter any complications related to arterial catheterization.

Our study has several limitations. Its monocentric retrospective nature, the restricted population, and the absence of a real control group did not allow a strict comparison. The results are limited to a specific strategy of distal to proximal revascularization and may not be reproducible in other conditions.

\section{CONCLUSIONS}

Mechanical treatment of internal carotid dissection tandem occlusion by using a distal to proximal triaxial strategy looks safe and effective compared with isolated intracranial occlusion stroke. The conservative approach of ICD, considering stent placement only after intracranial revascularization, in case of circle of Willis insufficiency, may be a reliable and safe strategy, reducing the need for systematic double antiplatelet therapy in the postoperative period. Randomized, multicenter trials are required to potentially confirm these results and to identify further clinical and radiologic factors contributing to a good outcome.

Disclosures: Alain Bonafé-UNRELATED: Consultancy: Covidien; ev3; Grants/ Grants Pending: Covidien*; Vincent Costalat—UNRELATED: Consultancy: Sequent Medical, Balt, Codman, Stryker; Payment for Lectures (including service on Speakers Bureaus): Stryker, Balt, Payment for Development of Educational Presentations: Covidien Payment for Development of Educational Presentations: Medtronic, Stryker. *Money paid to the institution.

\section{REFERENCES}

1. Engelter ST, Rutgers MP, Hatz F, et al. Intravenous thrombolysis in stroke attributable to cervical artery dissection. Stroke 2009;40: 3772-76 CrossRef Medline

2. Benninger DH, Georgiadis D, Kremer C, et al. Mechanism of ischemic infarct in spontaneous carotid dissection. Stroke 2004;35: 482-85 CrossRef Medline

3. Rubiera M, Ribo M, Delgado-Mederos R, et al. Tandem internal carotid artery/middle cerebral artery occlusion: an independent predictor of poor outcome after systemic thrombolysis. Stroke 2006;37:2301-05 CrossRef Medline

4. Linfante I, Llinas RH, Selim M, et al. Clinical and vascular outcome in internal carotid artery versus middle cerebral artery occlusions after intravenous tissue plasminogen activator. Stroke 2002;33: 2066-71 CrossRef Medline

5. Hacke W, Kaste M, Bluhmki E, et al; ECASS Investigators. Thrombolysis with alteplase 3 to $\mathbf{4} .5$ hours after acute ischemic stroke. N Engl J Med 2008;359:1317-29 CrossRef Medline

6. del Zoppo GJ, Poeck K, Pessin MS, et al. Recombinant tissue plasminogen activator in acute thrombotic and embolic stroke. Ann Neurol 1992;32:78-86 CrossRef Medline

7. Kim YS, Garami Z, Mikulik R, et al; CLOTBUST Collaborators. Early recanalization rates and clinical outcomes in patients with tandem internal carotid artery/middle cerebral artery occlusion and isolated middle cerebral artery occlusion. Stroke 2005;36:869-71 CrossRef Medline

8. Saver JL, Goyal M, Bonafe A, et al; SWIFT PRIME Investigators. Stent-retriever thrombectomy after intravenous t-PA vs. t-PA alone in stroke. $N$ Engl J Med 2015;372:2285-95 CrossRef Medline

9. Goyal M, Demchuk AM, Menon BK, et al; ESCAPE Trial Investigators. Randomized assessment of rapid endovascular treatment of ischemic stroke. $N$ Engl J Med 2015;372:1019-30 CrossRef Medline

10. Jovin T, Chamorro A, Cobo E, et al; REVASCAT Trial Investigators. Thrombectomy within $\mathbf{8}$ hours after symptom onset in ischemic stroke. N Engl J Med 2015;372:2296-306 CrossRef Medline

11. Campbell BCV, Mitchell PJ, Kleinig TJ, et al; EXTEND-IA Investiga- tors. Endovascular therapy for ischemic stroke with perfusion-imaging selection. $N$ Engl J Med 2015;372:1009-18 CrossRef Medline

12. Berkhemer O, Fransen P, Beumer D, et al. A randomized trial of intraarterial treatment for acute ischemic stroke. N Engl J Med 2015; 372:11-20 CrossRef Medline

13. Fischer U, Mono M-L, Schroth G, et al. Endovascular therapy in 201 patients with acute symptomatic occlusion of the internal carotid artery. Eur J Neurol 2013;20:1017-24, e87 CrossRef Medline

14. Kappelhof M, Marquering HA, Berkhemer OA, et al. Intra-arterial treatment of patients with acute ischemic stroke and internal carotid artery occlusion: a literature review. J Neurointerv Surg 2015; 7:8-15 CrossRef Medline

15. Kwak HS, Hwang SB, Jin GY, et al. Predictors of functional outcome after emergency carotid artery stenting and intra-arterial thrombolysis for treatment of acute stroke associated with obstruction of the proximal internal carotid artery and tandem downstream occlusion. AJNR Am J Neuroradiol 2013;34:841-46 CrossRef Medline

16. Lavallée PC, Mazighi M, Saint-Maurice JP, et al. Stent-assisted endovascular thrombolysis versus intravenous thrombolysis in internal carotid artery dissection with tandem internal carotid and middle cerebral artery occlusion. Stroke 2007;38:2270-74 CrossRef Medline

17. Baumgartner RW, Georgiadis D, Nedeltchev K, et al. Stent-assisted endovascular thrombolysis versus intravenous thrombolysis in internal carotid artery dissection with tandem internal carotid and middle cerebral artery occlusion. Stroke 2008;39:e27-28 CrossRef Medline

18. Machi P, Lobotesis K, Maldonado IL, et al. Endovascular treatment of tandem occlusions of the anterior cerebral circulation with Solitaire FR thrombectomy system: initial experience. Eur J Radiol 2012;81:3479-84 CrossRef Medline

19. Malik AM, Vora NA, Lin R, et al. Endovascular treatment of tandem extracranial/intracranial anterior circulation occlusions: preliminary single-center experience. Stroke 2011;42:1653-57 CrossRef Medline

20. Matsubara N, Miyachi S, Tsukamoto N, et al. Endovascular intervention for acute cervical carotid artery occlusion. Acta Neurochir (Wien) 2013;155:1115-23 CrossRef Medline

21. Mourand I, Brunel H, Vendrell JF, et al. Endovascular stent-assisted thrombolysis in acute occlusive carotid artery dissection. Neuroradiology 2010;52:135-40 CrossRef Medline

22. Suh DC, Kim JK, Choi CG, et al. Prognostic factors for neurologic outcome after endovascular revascularization of acute symptomatic occlusion of the internal carotid artery. AJNR Am J Neuroradiol 2007;28:1167-71 CrossRef Medline

23. Pereira V, Gralla J, Davalos A, et al. Prospective, multicentre, singlearm study of mechanical thrombectomy using Solitaire flow restoration in acute ischemic stroke: STAR. Stroke 2014;44:2802-07 CrossRef Medline

24. Saver JL, Jahan R, Levy EI, et al. Solitaire flow restoration device versus the Merci retriever in patients with acute ischaemic stroke (SWIFT): a randomised, parallel-group, non-inferiority trial. Lancet 2012;380:1241-49 CrossRef Medline

25. Nogueira RG, Lutsep HL, Gupta R, et al; TREVO 2 Trialists. Trevo versus Merci retrievers for thrombectomy revascularisation of large vessel occlusions in acute ischaemic stroke (TREVO 2): a randomised trial. Lancet 2012;380:1231-40 CrossRef Medline

26. Ciccone A, Valvassori L, Nichelatti M, et al; SYNTHESIS Expansion Investigators. Endovascular treatment for acute ischemic stroke. N Engl J Med 2013;368:904-13 CrossRef Medline

27. Broderick JP, Palesch YY, Demchuk AM, et al; Interventional Management of Stroke (IMS) III Investigators. Endovascular therapy after intravenous t-PA versus t-PA alone for stroke. $N$ Engl $\mathrm{J} \mathrm{Med}$ 2013;368:893-903 CrossRef Medline

28. Danière F, Lobotesis $\mathrm{K}$, Machi $\mathrm{P}$, et al. Patient selection for stroke endovascular therapy: DWI-ASPECTS thresholds should vary among age groups_-insights from the RECOST study. AJNR Am J Neuroradiol 2015;36:32-39 CrossRef Medline

29. Costalat V, Machi P, Lobotesis K, et al. Rescue, combined, and stand- 
alone thrombectomy in the management of large vessel occlusion stroke using the Solitaire device: a prospective 50-patient singlecenter study - timing, safety, and efficacy. Stroke 2011;42:1929-35 CrossRef Medline

30. Abud DG, Spelle L, Piotin M, et al. Venous phase timing during balloon test occlusion as a criterion for permanent internal carotid artery sacrifice. AJNR Am J Neuroradiol 2005;26:2602-09 Medline

31. Hacke W, Kaste M, Fieschi C, et al. Randomised double-blind placebo-controlled trial of thrombolytic therapy with intravenous alteplase in acute ischaemic stroke (ECASS II): Second EuropeanAustralasian Acute Stroke Study Investigators. Lancet 1998;352: 1245-51 Medline

32. Bluhmki E, Chamorro A, Dávalos A, et al. Stroke treatment with alteplase given 3.0-4.5 h after onset of acute ischaemic stroke (ECASS III): additional outcomes and subgroup analysis of a randomised controlled trial. Lancet Neurol 2009;8:1095-102 CrossRef Medline

33. The National Institute of Neurological Disorders and Stroke (NINDS) rt-PA Stroke Trial Study Group. Tissue plasminogen activator for acute ischemic stroke. $N$ Engl J Med 1995;333:1581-87 CrossRef Medline

34. Clark WM, Wissman S, Albers GW et al. Recombinant tissue-type plasminogen activator (Alteplase) for ischemic stroke 3 to 5 hours after symptom onset: The ATLANTIS Study-a randomized controlled trial. JAMA 1999;282:2019-26 CrossRef Medline

35. Saver JL, Goyal M, Bonafe A, et al; SWIFT PRIME Investigators. Solitaire ${ }^{\mathrm{TM}}$ with the Intention for Thrombectomy as Primary En- dovascular Treatment for Acute Ischemic Stroke (SWIFT PRIME) trial: protocol for a randomized, controlled, multicenter study comparing the Solitaire revascularization device with IV tPA with IV tPA alone in acute ischemic stroke. Int J Stroke 2015;10:439-48 CrossRef Medline

36. Lovett JK, Coull AJ, Rothwell PM. Early risk of recurrence by subtype of ischemic stroke in population-based incidence studies. $\mathrm{Neu}$ rology 2004;62:569-73 CrossRef Medline

37. Marnane M, Ni Chroinin DN, Callaly E, et al. Stroke recurrence within the time window recommended for carotid endarterectomy. Neurology 2011;77:738-43 CrossRef Medline

38. Arauz A, Hoyos L, Espinoza C, et al. Dissection of cervical arteries: long-term follow-up study of $\mathbf{1 3 0}$ consecutive cases. Cerebrovasc Dis 2006;22:150-54 CrossRef Medline

39. Mpotsaris A, Bussmeyer M, Buchner $\mathrm{H}$, et al. Clinical outcome of neurointerventional emergency treatment of extra- or intracranial tandem occlusions in acute major stroke: antegrade approach with Wallstent and Solitaire stent retriever. Clin Neuroradiol 2013;23: 207-15 CrossRef Medline

40. Spiotta AM, Lena J, Vargas J, et al. Proximal to distal approach in the treatment of tandem occlusions causing an acute stroke. J Neurointerv Surg 2015;7:164-69 CrossRef Medline

41. Papanagiotou $\mathrm{P}$, Roth $\mathrm{C}$, Walter $\mathrm{S}$, et al. Carotid artery stenting in acute stroke. J Am Coll Cardiol 2011;58:2363-69 CrossRef Medline

42. Xianjun $\mathrm{H}$, Zhiming $\mathrm{Z}$. A systematic review of endovascular management of internal carotid artery dissections. Interv Neurol 2013;1: 164-70 CrossRef Medline 